\title{
General Formulation of Winding Factor for Fractional-Slot Concentrated Winding Design
}

\author{
Yuichi Yokoi $^{1 *}$, Tsuyoshi Higuchi ${ }^{1}$, Yasuhiro Miyamoto ${ }^{2}$ \\ ${ }^{1}$ Division of Electrical Engineering and Computer Science, Nagasaki University, 1-14 Bunkyo, Na- \\ gasaki, 852-8521 Japan \\ ${ }^{2}$ Yaskawa Electric Corporation, 2-13-1 Nishimiyaichi, Yukuhashi, Fukuoka, 824-8511 Japan \\ *yyokoi@nagasaki-u.ac.jp
}

\begin{abstract}
Fractional-slot winding configurations have attracted much attention due to the availability of concentrated windings and low cogging torque in permanent magnet brushless motors. For the design of the winding configurations, many design parameters must be determined. The winding factor provides a useful index for the optimal design. However, no general expressions of the winding factor have been derived for all the winding configurations. This paper performs the general formulation of the winding factor for the fractional-slot concentrated windings. The winding factor is redefined for stator windings without any information of the numbers of poles. For given stator windings, the optimal numbers of poles are determined from the obtained winding factors. The design strategy for the winding configurations is validated through a finite element method analysis.
\end{abstract}

\section{Nomenclature}

$\begin{aligned} c & \text { Number of repeatable groups } \\ f & \text { Frequency of stator current } \\ m & \text { Number of phases } \\ m^{\prime} & \text { Number of phase belts in a repeatable group } \\ p & \text { Number of pole pairs } \\ q & \text { Number of slots per pole per phase } \\ r & \text { Number of layers } \\ s & \text { Number of phase belts belonging to a phase in a repeatable group } \\ z & \text { Number of coils in a phase belt } \\ k_{\mathrm{d} \nu} & \text { Distribution factor in winding degrees } \\ k_{\mathrm{p} \nu} & \text { Pitch factor in winding degrees } \\ k_{\mathrm{r} \nu} & \text { Rotation factor in winding degrees } \\ k_{\mathrm{w} \nu} & \text { Winding factor in winding degrees } \\ F_{\text {coil }} & \text { Magnetomotive force (MMF) due to current of a coil } \\ F_{i} & \text { MMF due to winding current of the phase } i \text { in a repeatable group } \\ I_{\text {coil }} & \text { Current supplied to a coil } \\ I_{i} & \text { Current of the phase } i \text { in a repeatable group }\end{aligned}$




$\begin{aligned} I_{\text {peak }} & \text { Amplitude of phase current } \\ N & \text { Number of turns of a phase winding in a repeatable group } \\ N_{\text {coil }} & \text { Number of turns in a coil } \\ Q & \text { Number of slots in a repeatable group } \\ \beta & \text { Ratio of coil pitch to the maximum pitch or } \pi \text { in winding degrees } \\ \theta & \text { Angular coordinate in winding degrees } \\ \theta_{0} & \text { Phase of stator current } \\ \varphi_{\text {coil }} & \text { Axis of a coil } \\ \varphi_{i} & \text { Axis of the phase belt } i \\ \varphi_{i, j} & \text { Axis of the coil }(i, j) \\ \nu & \text { Harmonic order } \\ \omega & \text { Angular frequency of stator current }\end{aligned}$

\section{Introduction}

Fractional-slot winding configurations have attracted much attention in the production and development of permanent magnet (PM) brushless motors [1]. This is mainly due to the availability of non-overlapping or concentrated windings as well as low cogging torque. The concentrated windings inherently provide short end-windings for low copper loss. The combination of the concentrated windings and segmented stator structures can achieve a high slot fill factor and the automated manufacturing of winding for mass production [2-4]. In addition, the concentrated windings wound around alternate teeth or in a single layer are suited for fault-tolerant designs [5-7]. The low cogging torque is attributed to the slot/pole combination.

Winding factor provides a useful index in the design of the winding configurations - including the number of slots, the number of poles, and the winding layouts - and is used in the analytical calculations of inductances [8-11] and rotor losses [12-15]. For integral-slot windings, the winding factor is expressed in the general formulae. For the fractional-slot windings, several expressions are established for specified slot/pole combinations [16]. However, these expressions cannot cover all the fractional-slot winding configurations. For this reason, several methods have been proposed to determine the optimal winding configurations. In [17], a systematic method was proposed to determine the optimal winding layouts for given slot/pole combinations in three-phase configurations with the concentrated windings. By using this method, the slot/pole combinations for high machine performance were identified. In [18], this method was extended to cover four, five, and six-phase configurations and the fundamental winding factors, cogging torque indicators, and net radial force indicators were clarified for various slot/pole combinations. In [12], a method was presented to calculate the fundamental winding factors based on electromotive force (EMF) phasor diagrams; furthermore, harmonic components in the spatial distribution of magnetomotive force (MMF), which corresponded to the harmonic winding factors, were calculated to estimate Joule losses. In [19], by using the methods presented in $[12,17]$, the fundamental winding factors were calculated for various 
slot/pole combinations including a large number of poles. In [6,20], another systematic method was presented to determine the optimal winding layouts for given slot/pole combinations based on the star of slots, which represents the phasors of the EMF induced in each individual coil-side. By using this method, harmonics of the MMF were calculated to evaluate the winding configurations.

The general formulation of the winding factor for the fractional-slot windings may be hindered by many design parameters yet to be determined, namely, the slot/pole combination, the number of winding layers, the number of phase belts, and the coil pitch. For the integral-slot windings, only two design parameters, namely, the number of slots per pole per phase and the coil pitch, must be determined. This is because the integral-slot windings are inherently determined for a pole pair and have a restriction in the winding layout. This restriction is that "go" or "return" coil-sides belonging to a phase are inserted in adjacent slots. This simultaneously determines the number of phase belts. Indeed, an integral-slot winding configuration without the restriction was proposed and a different expression of the winding factor was derived for this configuration [21]. For this reason, this winding configuration may be regarded as a special kind of winding layout. The different configurations of the integral slot windings require different expressions for the winding factor.

In this paper, according to the typical configuration of the integral-slot windings, the configuration of the fractional-slot windings is restricted with respect to the winding layout. The stator winding is composed of concentrated winding coils to take advantage of the features. The coils construct one or two phase belts for each phase. In addition, the number of poles can be excluded from the design parameters required for the design of the winding configuration. The winding factor is redefined without the information of the number of poles because a stator winding generates rotating MMF independently of the number of poles of the rotor. Therefore, for the general formulation of the winding factor, the design parameters to be determined are the number of layers, the number of phase belts, and the number of slots or coils per phase belt.

This paper performs the general formulation of the winding factor for the fractional-slot windings that are composed of concentrated windings and have one or two phase belts per phase. In spite of these restrictions, the winding configuration includes the fractional-slot windings that are suitable for practical use and mass production. This is due to the above features of the concentrated windings. Regarding the restriction on the number of phase belts per phase, which is also imposed on the integral-slot winding configuration, the small number of phase belts achieves that of the contacts between phase windings to increase fault-tolerant capability. The general formulation covers all the slot/pole combinations under these restrictions to provide a unified design method, which has not previously been presented. Therefore, the general expression of the winding factor serves as a powerful tool to determine the stator winding configuration in motor designs without any procedures to obtain the optimal winding layout. For the fractional-slot concentrated windings, the winding factor is redefined independently of the number of poles and formulated through the analysis of the spatiotemporal distribution of the MMF. Using the obtained factors, the optimal numbers of poles are determined for the winding configurations. In addition, a finite element method (FEM) analysis is performed to validate the design of the winding configuration with the determination of the number of poles. 


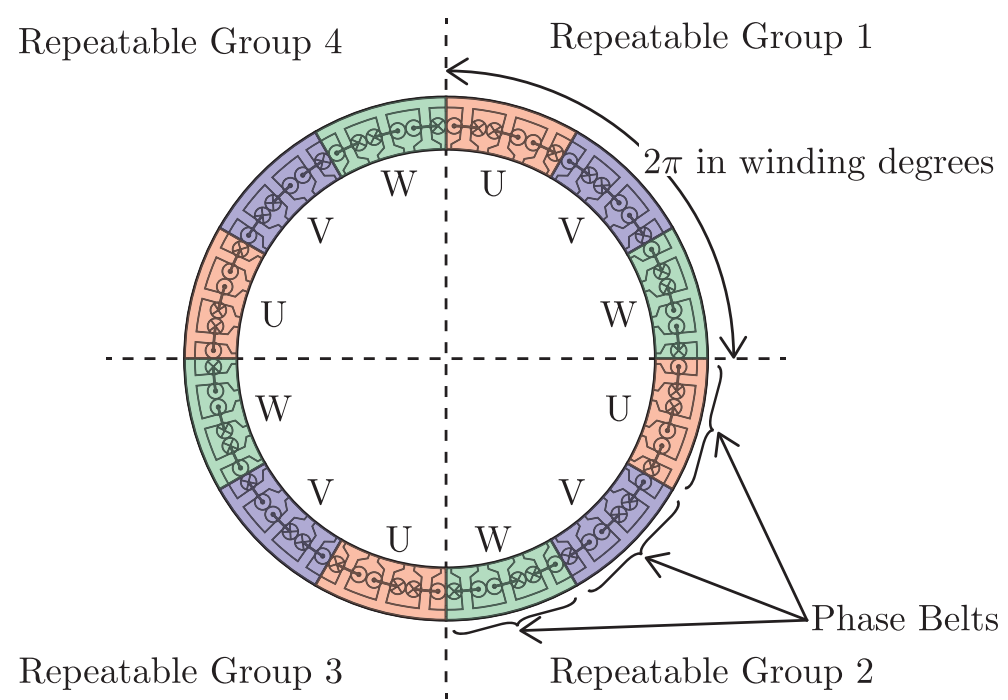

Fig. 1: Definitions of repeatable group, winding degree, and phase belt

\section{Winding Configuration}

This section describes the configuration of the stator windings that are analysed in this paper and defines technical terms, namely repeatable group, winding degree, and phase belt.

A conventional stator winding may include several identical sequences of coil-sides. The shortest identical sequences can be regarded as the minimum units of winding, called repeatable groups of the winding, as shown in Fig. 1. The repeatable groups exhibit identical spatial distributions of MMF in the corresponding regions of the air gap. That is, if the number of repeatable groups is $c$ in a stator winding, there are $c$ periods of the MMF distribution in the whole region of the air gap. Therefore, the analysis of a repeatable group is equivalent to that of the whole winding.

In a repeatable group, the circumferential position of the air gap is measured in winding degrees. The winding degree is defined as the measurement that associates the corresponding region of the air gap with $2 \pi$, as shown in Fig. 1. For integral slot windings, the winding degree is equivalent to the electrical degree.

The stator windings that are analysed in this paper fulfil the following conditions.

1) The arrangement of coils is symmetric with respect to phase belt.

2) All coils have the same turns.

3) All coils have the same pitch. The coil pitch is fixed at the slot pitch; this winding is called concentrated winding.

4) Coil-sides are inserted into slots in a single or double layer.

5) For the number of phases, $m$, each repeatable group consists of $m$ or $2 m$ phase belts.

The phase belt is defined as the group of adjacent coil-sides belonging to a phase, as shown in Fig. 1. Condition 3 implies that a phase belt includes more than one coil-side. In condition 1, the phase belt corresponds to the minimum unit of coil arrangements.

The design of a stator winding configuration begins with the determination of the number of phase belts, which depends on the number of phases. The number of phase belts in the repeatable group 
is represented by $m^{\prime}$. If $m^{\prime}$ is odd, then the winding is constructed from $m^{\prime}$ phase windings. If $m^{\prime}$ is even, then the number of needed phase windings decreases by half, that is, to $m^{\prime} / 2$. The reason is as follows. When the repeatable group has an even number of phase belts, the phase belts can be divided into $m^{\prime} / 2$ pairs. Each pair is composed of two phase belts that are located at the positions at a distance of $\pi$ in winding degrees. The two phase belts of a pair are supplied with currents whose phases are different by $\pi$ from each other so that the repeatable group generates a rotating magnetic field. The supply of the current in antiphase to a phase belt is equivalent to that of the current in phase to the phase belt with the opposite polarity. Thus, condition 1 is modified as

$\left.1^{\prime}\right)$ The arrangement of coils is symmetric with respect to phase.

For $m^{\prime}$ phase belts, the number of phase belts belonging to a phase, $s$, is given by

$$
s=\mathrm{GCD}\left(m^{\prime}, 2\right)
$$

where $\operatorname{GCD}(x, y)$ is the greatest common divisor of $x$ and $y$. Hence, $s=1$ or 2 . Using $m^{\prime}$ and $s$, the number of needed phases is determined by

$$
m=\frac{m^{\prime}}{s}
$$

According to the number of winding layers and the number of phase belts, the winding configurations are classified as follows.

- Single-layer winding

- One phase belt for each phase

- Two phase belts for each phase

- Double-layer winding

- One phase belt for each phase

- Two phase belts for each phase

The analysis is performed for each of the classified winding configurations.

In the following sections, a repeatable group of the stator winding is analysed using the coordinate $\theta$ in winding degrees. The winding factor and the associated factors, namely, pitch factor and distribution factor are redefined in winding degrees.

\section{Pitch Factor}

A general expression of the pitch factor is described in winding degrees. For a repeatable group of the stator winding, the maximum pitch of a coil is $\pi$ in winding degrees. For a coil pitch $\beta \pi$, Fig. 2 shows a coil in a repeatable group and the spatial distribution of the MMF at a current supply. The coil pitch is defined as the arc width between the centres of the openings of the slots carrying the coil-sides because the magnetic fields of coil-sides in a slot across the air gap are governed by the distribution of magnetic reluctance due to the stator shape. In figures of MMF distributions, as in 


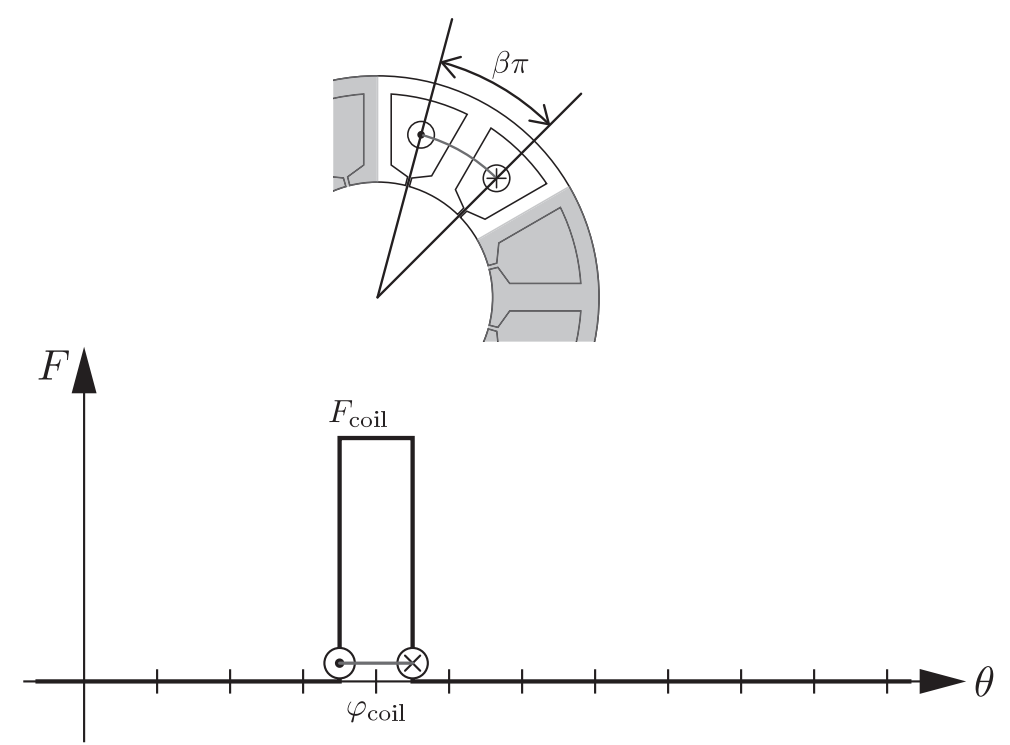

Fig. 2: Coil around a tooth with a slot pitch of $\beta \pi$ and spatial distribution of the MMF due to the coil

Fig. 2, the horizontal axis does not indicate the reference value of MMF for simplicity. Indeed, the following formulation is not dependent on the reference value of MMF.

The MMF distribution of the coil is expressed by the following Fourier series:

$$
F_{\text {coil }}\left(t, \theta ; \varphi_{\text {coil }}\right)=\frac{2 N_{\text {coil }} I_{\text {coil }}(t)}{\pi} \sum_{\nu=1}^{\infty} \frac{1}{\nu} k_{\mathrm{p} \nu} \cos \left[\nu\left(\theta-\varphi_{\text {coil }}\right)\right]
$$

where $\varphi_{\text {coil }}$ denotes the coil axis, $N_{\text {coil }}$ is the number of turns, $I_{\text {coil }}$ denotes the supplied current, and $k_{\mathrm{p} \nu}$ is the pitch factor in winding degrees defined as

$$
k_{\mathrm{p} \nu}=\sin \left(\frac{\pi \nu \beta}{2}\right)
$$

In this paper, the coil pitch is fixed at the slot pitch. For the number of slots, $Q$, the slot pitch is expressed as $2 \pi / Q$. Thus, the pitch factor can be written as

$$
k_{\mathrm{p} \nu}=\sin \left(\frac{\pi \nu}{Q}\right)=\sin \left(\frac{\pi \nu r}{2 s m z}\right)
$$

where $r$ is the number of layers and $z$ is the number of coils in a phase belt, and the following relation is used:

$$
Q=\frac{2 s m z}{r}
$$

In the integral-slot winding configurations, the ratio $\beta$ is generally selected as $(Q-2 n) / Q$ for $n=0,1,2$. Therefore, the pitch factor for the integral-slot windings is

$$
k_{\mathrm{p} \nu}=\sin \left[\frac{\pi \nu(Q-2 n)}{2 Q}\right] .
$$




\section{Distribution Factor}

For the stator windings on the above conditions, a general expression of the distribution factor is derived in winding degrees. The formulation is classified in terms of the number of layers and the number of phase belts for each phase.

\subsection{Single-Layer Winding}

The distribution factor is formulated for single-layer concentrated windings, $r=1$. In the windings, coils are wound around alternate teeth, and the unwound teeth establish flux return paths. The return path of an unwound tooth is used by the flux passing through the coils of adjacent teeth. For an effective utilisation of the unwound teeth, adjacent coils belonging to a phase should be wound with the same polarity.

The single-layer windings in which each phase belt has $z$ coils can be constructed in stators with $Q$ slots or teeth:

$$
Q=\frac{2 s m z}{r}=2 s m z
$$

In the windings, the axis of the coil $( \pm i, j)$, which is the $j$-th coil in the phase belt $\pm i$ belonging to the phase $i$, is expressed as

$$
\varphi_{ \pm i, j}=\varphi_{ \pm i}+\frac{2 \pi}{s m z}\left(j-\frac{z+1}{2}\right)
$$

where $\varphi_{ \pm i}$ indicates the axis of the phase belt $\pm i$. The phase belt $-i$ appears for $s=2$. The axes of these phase belts have the relation: $\varphi_{-i}=\varphi_{i}+\pi$.

\subsubsection{One Phase Belt Per Phase}

For one phase belt per phase, $s=1$, the winding layout for $m=3$ and $z=2$ is, as an example, shown in Fig. 3a. Each phase winding generates the spatial distribution of the MMF, as shown in the figure.

The MMF distribution due to the winding current of the phase $i$ is expressed as

$$
F_{i}(t, \theta)=\sum_{j=1}^{z} F_{\text {coil }}\left(t, \theta ; \varphi_{i, j}\right)
$$

By substituting (3) and (9) into (10), the MMF distribution is

$$
F_{i}(t, \theta)=\frac{2 N I_{i}(t)}{\pi} \sum_{\nu=1}^{\infty} \frac{1}{\nu} k_{\mathrm{p} \nu} k_{\mathrm{d} \nu} \cos \left[\nu\left(\theta-\varphi_{i}\right)\right],
$$

where $N\left(=s z N_{\text {coil }}\right)$ is the number of turns of the phase winding, $I_{i}(t)$ denotes the current of the phase $i$, and the distribution factor $k_{\mathrm{d} \nu}$ is formulated as

$$
k_{\mathrm{d} \nu}=\frac{\sin (\nu \pi / s m)}{z \sin (\nu \pi / s m z)} .
$$



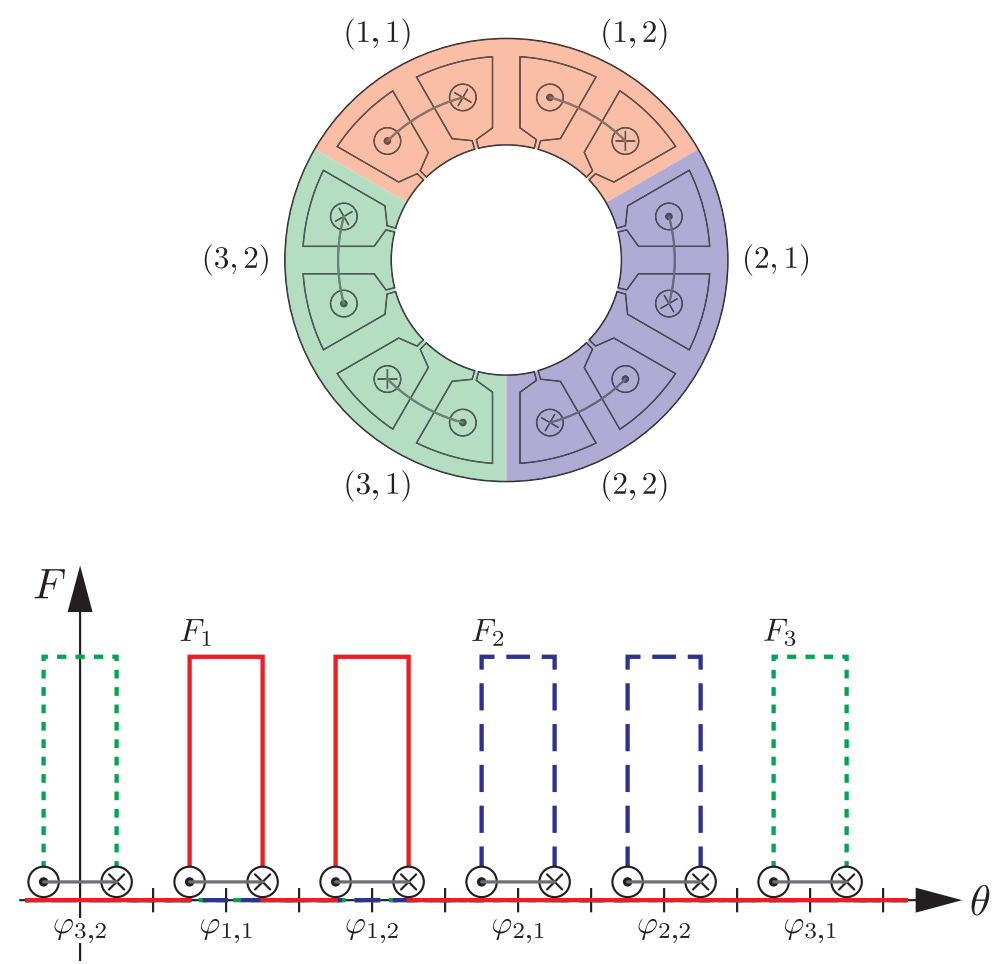

(a)
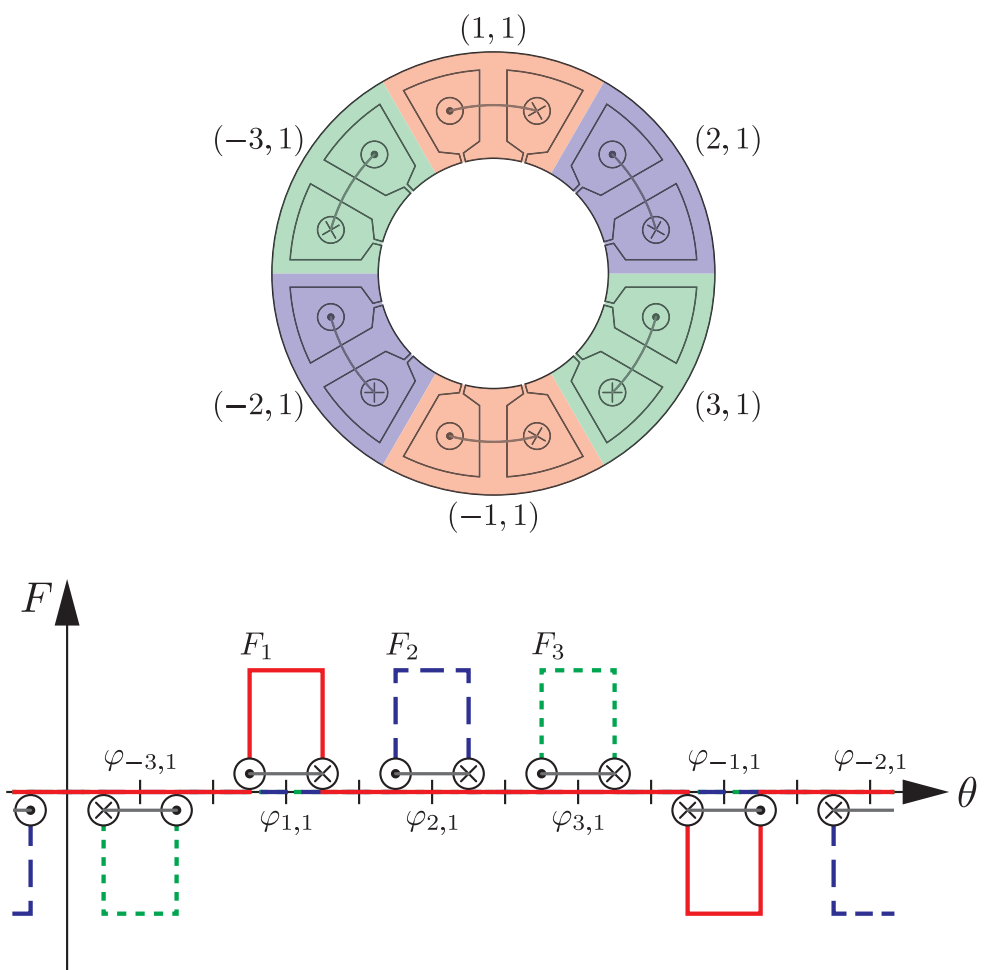

(b)

Fig. 3: Winding layout and spatial distribution of the MMF due to a phase winding for $r=1, m=3$, and (a) $s=1$ and $z=2$ and (b) $s=2$ and $z=1$

\subsubsection{Two Phase Belts Per Phase}

For two phase belts per phase, $s=2$, the winding layout for $m=3$ and $z=1$ is, as an example, shown in Fig. 3b. Each phase winding generates the spatial distribution of the MMF, as shown in the figure. 
By using (3) and (9), the MMF distribution due to the winding current of the phase $i$ is

$$
\begin{aligned}
F_{i}(t, \theta) & =\sum_{j=1}^{z}\left\{F_{\text {coil }}\left(t, \theta ; \varphi_{i, j}\right)-F_{\text {coil }}\left(t, \theta ; \varphi_{-i, j}\right)\right\} \\
& =\frac{2 N I_{i}(t)}{\pi} \sum_{\nu=1}^{\infty} \frac{1}{\nu} k_{\mathrm{p} \nu} k_{\mathrm{d} \nu} \cos \left[\nu\left(\theta-\varphi_{i}\right)\right]
\end{aligned}
$$

where the distribution factor $k_{\mathrm{d} \nu}$ is formulated as

$$
k_{\mathrm{d} \nu}= \begin{cases}\frac{\sin (\nu \pi / s m)}{z \sin (\nu \pi / s m z)} & \text { if } \nu \text { is odd } \\ 0 & \text { if } \nu \text { is even }\end{cases}
$$

\subsection{Double-Layer Winding}

The distribution factor is formulated for double-layer concentrated windings, $r=2$. In the windings, coils are wound around all teeth, and each coil has a polarity opposite to the adjacent coils in each phase belt. If the adjacent coils have the same polarity, then a slot between the wound teeth contains a "go" coil-side of one coil and a "return" coil-side of the other coil. Thus, current flowing in the slot is cancelled out magnetically. These coil-sides provide no contribution to the magnetic field around the slot. Therefore, the adjacent coils with the same polarity are not implemented.

The double-layer windings in which each phase belt has $z$ coils can be constructed in stators with $Q$ slots or teeth:

$$
Q=\frac{2 s m z}{r}=s m z
$$

In the windings, the position of the coil $( \pm i, j)$ is expressed as $(9)$.

\subsubsection{One Phase Belt Per Phase}

For one phase belt per phase, $s=1$, the winding layout for $m=3$ and $z=3$ is, as an example, shown in Fig. 4a. Each phase winding generates the spatial distribution of the MMF, as shown in the figure.

By using (3) and (9), the MMF distribution due to the winding current of the phase $i$ is

$$
\begin{aligned}
& F_{i}(t, \theta) \\
& \quad=\sum_{j=1}^{z}(-1)^{j-1} F_{\text {coil }}\left(t, \theta ; \varphi_{i, j}\right) \\
& \quad= \begin{cases}\frac{2 N I_{i}(t)}{\pi} \sum_{\nu=1}^{\infty} \frac{1}{\nu} k_{\mathrm{p} \nu} k_{\mathrm{d} \nu} \cos \left[\nu\left(\theta-\varphi_{i}\right)\right] & \text { if } z \text { is odd }, \\
-\frac{2 N I_{i}(t)}{\pi} \sum_{\nu=1}^{\infty} \frac{1}{\nu} k_{\mathrm{p} \nu} k_{\mathrm{d} \nu} \sin \left[\nu\left(\theta-\varphi_{i}\right)\right] & \text { if } z \text { is even, }\end{cases}
\end{aligned}
$$



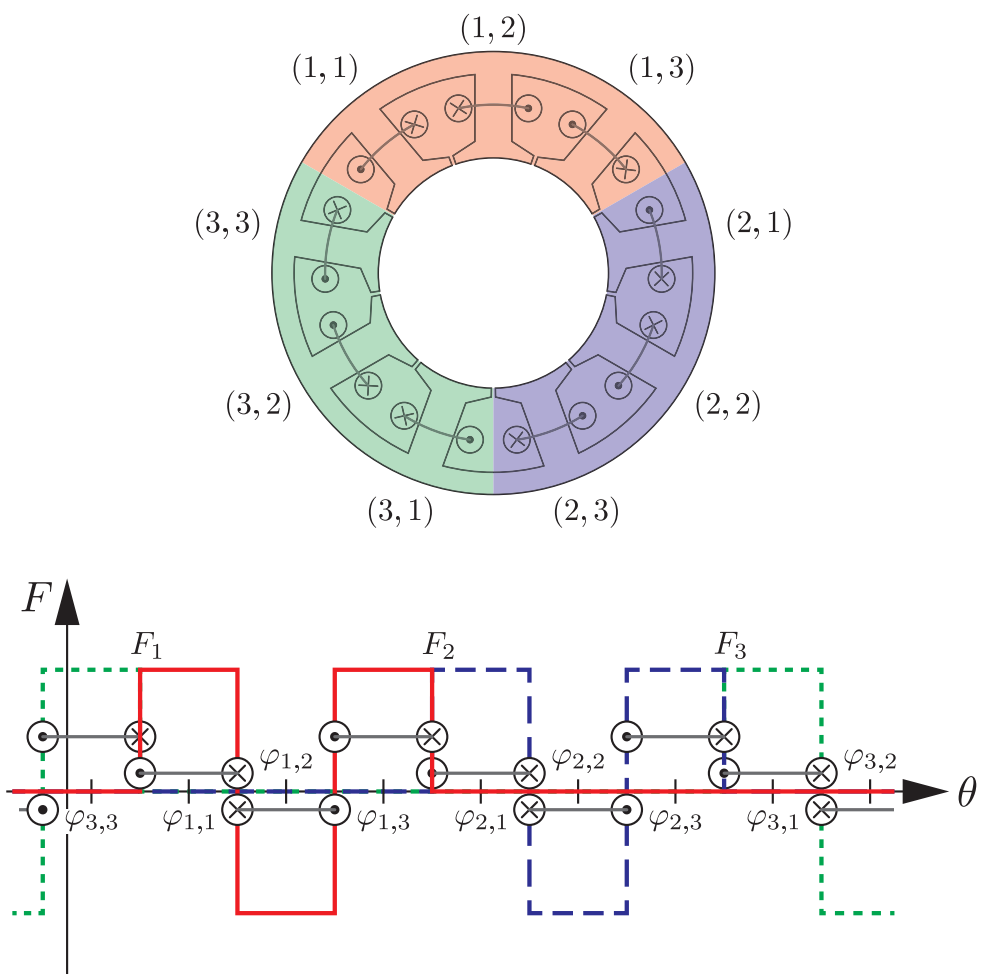

(a)
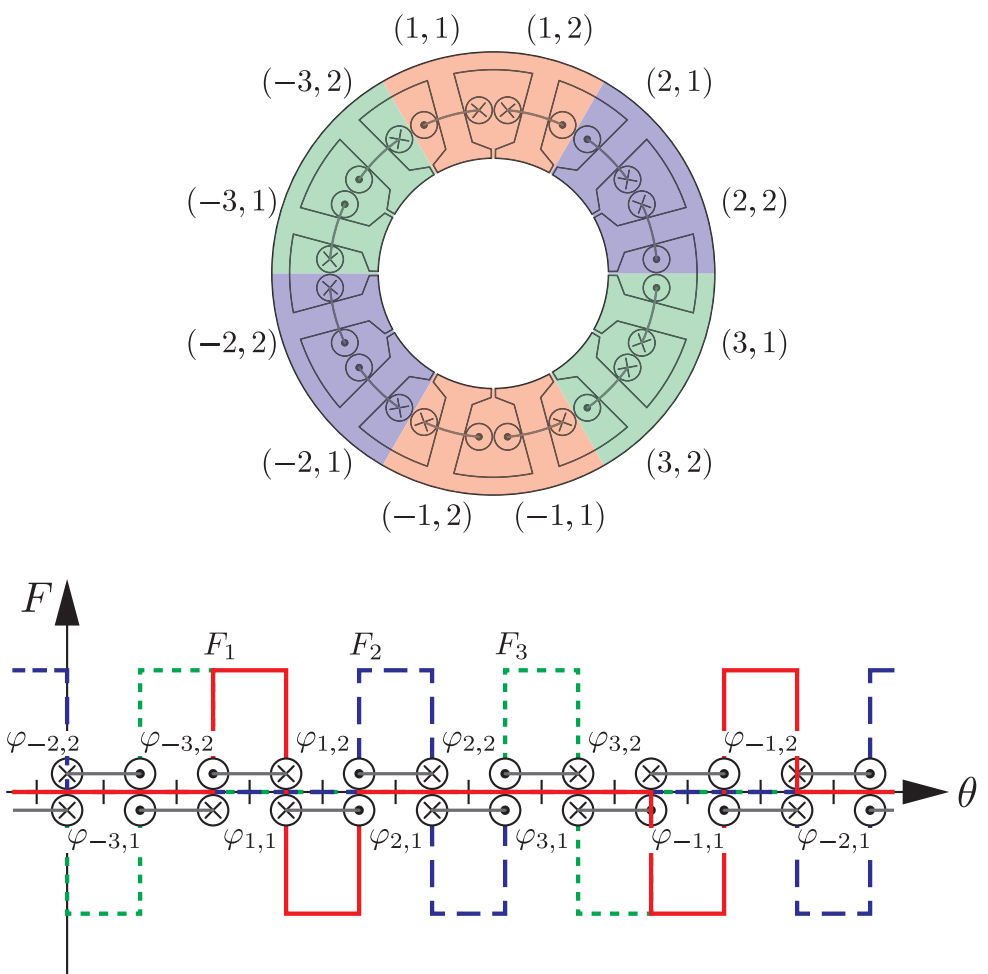

(b)

Fig. 4: Winding layout and spatial distribution of the MMF due to a phase winding for $r=2, m=3$, and (a) $s=1$ and $z=3$ and (b) $s=2$ and $z=2$

where the distribution factor $k_{\mathrm{d} \nu}$ is formulated as

$$
k_{\mathrm{d} \nu}= \begin{cases}\frac{\cos (\nu \pi / s m)}{z \cos (\nu \pi / s m z)} & \text { if } z \text { is odd } \\ \frac{\sin (\nu \pi / s m)}{z \cos (\nu \pi / s m z)} & \text { if } z \text { is even }\end{cases}
$$


Table 1: General expressions of the distribution factor

\begin{tabular}{|c|c|c|c|c|c|}
\hline \multirow[b]{2}{*}{$r$} & $s$ & \multicolumn{2}{|c|}{1} & \multicolumn{2}{|c|}{2} \\
\hline & 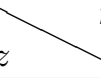 & odd & even & odd & even \\
\hline \multirow{2}{*}{1} & odd & \multicolumn{3}{|c|}{$\sin (\nu \pi / s m)$} & \multirow{6}{*}{$k_{\mathrm{d} \nu}=0$} \\
\hline & even & & $z \sin (\nu$ & $m z)$ & \\
\hline \multirow{4}{*}{2} & odd & $k_{\mathrm{d} \nu}$ & $\cos (\nu$ & $m)$ & \\
\hline & & & $z \cos (\nu$ & $m z)$ & \\
\hline & \multirow[t]{2}{*}{ even } & \multicolumn{3}{|c|}{$k_{\mathrm{d} \nu}=\frac{\sin (\nu \pi / s m)}{}$} & \\
\hline & & & $z \cos (\nu$ & $m z)$ & \\
\hline
\end{tabular}

\subsubsection{Two Phase Belts Per Phase}

For two phase belts per phase, $s=2$, the winding layout for $m=3$ and $z=2$ is, as an example, shown in Fig. 4b. Each phase winding generates the spatial distribution of the MMF, as shown in the figure.

By using (3) and (9), the MMF distribution due to the winding current of the phase $i$ is

$$
\begin{aligned}
& F_{i}(t, \theta) \\
& =\sum_{j=1}^{z}(-1)^{j-1}\left\{F_{\text {coil }}\left(t, \theta ; \varphi_{i, j}\right)-F_{\text {coil }}\left(t, \theta ; \varphi_{-i, j}\right)\right\} \\
& \quad= \begin{cases}\frac{2 N I_{i}(t)}{\pi} \sum_{\nu=1}^{\infty} \frac{1}{\nu} k_{\mathrm{p} \nu} k_{\mathrm{d} \nu} \cos \left[\nu\left(\theta-\varphi_{i}\right)\right] & \text { if } z \text { is odd }, \\
-\frac{2 N I_{i}(t)}{\pi} \sum_{\nu=1}^{\infty} \frac{1}{\nu} k_{\mathrm{p} \nu} k_{\mathrm{d} \nu} \sin \left[\nu\left(\theta-\varphi_{i}\right)\right] & \text { if } z \text { is even, }\end{cases}
\end{aligned}
$$

where the distribution factor $k_{\mathrm{d} \nu}$ is formulated as

$$
k_{\mathrm{d} \nu}= \begin{cases}\frac{\cos (\nu \pi / s m)}{z \cos (\nu \pi / s m z)} & \text { if } \nu \text { is odd and } z \text { is odd } \\ \frac{\sin (\nu \pi / s m)}{z \cos (\nu \pi / s m z)} & \text { if } \nu \text { is odd and } z \text { is even } \\ 0 & \text { if } \nu \text { is even. }\end{cases}
$$

The obtained general expressions of the distribution factor for the classified winding configurations are summarised in Table 1. In the integral-slot winding configurations, the distribution factor is written as

$$
k_{\mathrm{d} \nu}=\frac{\sin (\nu \pi / s m)}{z \sin (\nu \pi / s m z)}=\frac{\sin (\nu \pi / 2 m)}{q \sin (\nu \pi / 2 m q)},
$$

where $s$ is fixed at 2 for the integral-slot windings and $z$ corresponds to the number of slots per pole per phase, $q$. 


\section{$5 \quad$ Winding Factor}

A repeatable group of the stator winding supplied with current generates a spatiotemporal distribution of the MMF in the air gap. The MMF distribution consists of forward and backward-rotating components, which are so-called rotating magnetic fields. The amplitudes of the components depend on the winding configuration. The relative values are expressed by the winding factor. In this section, the winding factor, which is redefined in winding degrees, is derived from the spatiotemporal distribution of the MMF in a repeatable group.

The MMF distribution of the stator winding is the superposition of the MMF distributions of the phase windings. The phase MMF distribution is expressed by (11), (13), (16), and (18) for the classified winding configurations. Hence, if $r=1$, or $r=2$ and $z$ is odd, the MMF distribution of the phase $i$ is

$$
F_{i}(t, \theta)=\frac{2 N I_{i}(t)}{\pi} \sum_{\nu=1}^{\infty} \frac{1}{\nu} k_{\mathrm{p} \nu} k_{\mathrm{d} \nu} \cos \left[\nu\left(\theta-\varphi_{i}\right)\right] .
$$

If $r=2$ and $z$ is even, then the distribution is

$$
F_{i}(t, \theta)=-\frac{2 N I_{i}(t)}{\pi} \sum_{\nu=1}^{\infty} \frac{1}{\nu} k_{\mathrm{p} \nu} k_{\mathrm{d} \nu} \sin \left[\nu\left(\theta-\varphi_{i}\right)\right] .
$$

Because the coil arrangement is symmetric with respect to phase, the axis of the phase belt $i$ is determined to be

$$
\varphi_{i}=\frac{2 \pi}{s m}\left(i-\frac{m+1}{2}\right) .
$$

In the $m$-phase current supplied to the stator winding, the current of the phase $i$ is expressed as

$$
I_{i}(t)=I_{\text {peak }} \cos \left(\omega t-\varphi_{i}+\theta_{0}\right)
$$

where $I_{\text {peak }}$ denotes the amplitude, $\omega$ denotes the electrical angular frequency, and $\theta_{0}$ denotes the phase that regulates current vector control.

If $r=1$, or $r=2$ and $z$ is odd, using (21), (23), and (24), then the MMF distribution of the stator winding current is

$$
\begin{aligned}
& F(t, \theta)= \sum_{i=1}^{m} F_{i}(t, \theta) \\
&=\frac{m}{2} \cdot \frac{2 N I}{\pi} \sum_{\nu=1}^{\infty} \frac{1}{\nu}\left\{k_{\mathrm{p} \nu} k_{\mathrm{d} \nu} k_{\mathrm{r} \nu-1} \cos (\omega t-\nu \theta)\right. \\
& \\
&\left.+k_{\mathrm{p} \nu} k_{\mathrm{d} \nu} k_{\mathrm{r} \nu+1} \cos (\omega t+\nu \theta)\right\}
\end{aligned}
$$

where $k_{\mathrm{r} \nu}$ is defined as

$$
k_{\mathrm{r} \nu}=\frac{\sin (\pi \nu / s)}{m \sin (\pi \nu / s m)}
$$

This factor determines the existence and the rotational direction of the rotating magnetic fields. For this reason, the factor is called rotation factor in this paper. If $r=2$ and $z$ is even, using (22), (23), 
Table 2: Winding factors and rotating MMF components for $r=1, s=2, m=3$, and $z=1$

\begin{tabular}{|c|c|c|c|c|c|c|c|}
\hline \multirow{2}{*}{$\begin{array}{c}\text { Order } \\
\nu\end{array}$} & \multicolumn{5}{|c|}{ Winding Factors } & \multicolumn{2}{|c|}{ Rotating MMF } \\
\hline & $k_{\mathrm{p} \nu}$ & $k_{\mathrm{d} \nu}$ & $k_{\mathrm{w} \nu}$ & $k_{\mathrm{r} \nu-1}$ & $k_{\mathrm{r} \nu+1}$ & forward & backward \\
\hline 1 & 0.2588 & 1.0000 & 0.2588 & 1.0000 & 0.0000 & 0.2588 & - \\
\hline 2 & 0.5000 & 0.0000 & 0.0000 & 0.6667 & -0.3333 & 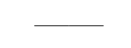 & 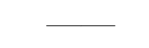 \\
\hline 3 & 0.7071 & 1.0000 & 0.7071 & 0.0000 & 0.0000 & 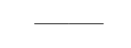 & $\bar{L}$ \\
\hline 4 & 0.8660 & 0.0000 & 0.0000 & -0.3333 & 0.6667 & & - \\
\hline 5 & 0.9659 & 1.0000 & 0.9659 & 0.0000 & 1.0000 & & 0.9659 \\
\hline 6 & 1.0000 & 0.0000 & 0.0000 & 0.6667 & 0.6667 & $\longrightarrow$ & - \\
\hline 7 & 0.9659 & 1.0000 & 0.9659 & 1.0000 & 0.0000 & 0.9659 & \\
\hline 8 & 0.8660 & 0.0000 & 0.0000 & 0.6667 & -0.3333 & & - \\
\hline 9 & 0.7071 & 1.0000 & 0.7071 & 0.0000 & 0.0000 & & - \\
\hline 10 & 0.5000 & 0.0000 & 0.0000 & -0.3333 & 0.6667 & & - \\
\hline 11 & 0.2588 & 1.0000 & 0.2588 & 0.0000 & 1.0000 & & 0.2588 \\
\hline 12 & 0.0000 & 0.0000 & 0.0000 & 0.6667 & 0.6667 & $\longrightarrow$ & ב \\
\hline 13 & -0.2588 & 1.0000 & -0.2588 & 1.0000 & 0.0000 & 0.2588 & 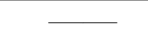 \\
\hline 14 & -0.5000 & 0.0000 & 0.0000 & 0.6667 & -0.3333 & & \\
\hline 15 & -0.7071 & 1.0000 & -0.7071 & 0.0000 & 0.0000 & & \\
\hline 16 & -0.8660 & 0.0000 & 0.0000 & -0.3333 & 0.6667 & & - \\
\hline 17 & -0.9659 & 1.0000 & -0.9659 & 0.0000 & 1.0000 & & 0.9659 \\
\hline 18 & -1.0000 & 0.0000 & 0.0000 & 0.6667 & 0.6667 & - & 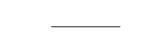 \\
\hline 19 & -0.9659 & 1.0000 & -0.9659 & 1.0000 & 0.0000 & 0.9659 & 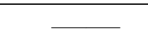 \\
\hline 20 & -0.8660 & 0.0000 & 0.0000 & 0.6667 & -0.3333 & & \\
\hline 21 & -0.7071 & 1.0000 & -0.7071 & 0.0000 & 0.0000 & & \\
\hline 22 & -0.5000 & 0.0000 & 0.0000 & -0.3333 & 0.6667 & & - \\
\hline 23 & -0.2588 & 1.0000 & -0.2588 & 0.0000 & 1.0000 & & 0.2588 \\
\hline 24 & 0.0000 & 0.0000 & 0.0000 & 0.6667 & 0.6667 & - & $\square$ \\
\hline
\end{tabular}

and (24), the MMF distribution of the stator winding current is

$$
\begin{aligned}
F(t, \theta)= & \sum_{i=1}^{m} F_{i}(t, \theta) \\
=\frac{m}{2} \cdot \frac{2 N I}{\pi} \sum_{\nu=1}^{\infty} \frac{1}{\nu} & \left\{k_{\mathrm{p} \nu} k_{\mathrm{d} \nu} k_{\mathrm{r} \nu-1} \sin (\omega t-\nu \theta)\right. \\
& \left.-k_{\mathrm{p} \nu} k_{\mathrm{d} \nu} k_{\mathrm{r} \nu+1} \sin (\omega t+\nu \theta)\right\} .
\end{aligned}
$$

In (25) and (27), the product of the pitch factor $k_{\mathrm{p} \nu}$ and the distribution factor $k_{\mathrm{d} \nu}$ is defined as the winding factor:

$$
k_{\mathrm{w} \nu}=k_{\mathrm{p} \nu} k_{\mathrm{d} \nu}
$$

For the three stator windings shown in Figs. 3b, 4a, and 4b, the winding factors are listed for the harmonic order with the rotating MMF components in Table 2, 3, and 4, respectively. The listed values are repeated with the period of $4 s m z / r$ for the order $\nu$ because of the periodicity of the factors. The tables present the first periods of the factors. As shown in these tables, the MMF components of the order for $k_{\mathrm{r} \nu-1}=1$ and $k_{\mathrm{r} \nu+1}=1$ rotate in the forward and backward directions, respectively. 
Table 3: Winding factors and rotating MMF components for $r=2, s=1, m=3$, and $z=3$

\begin{tabular}{|c|c|c|c|c|c|c|c|}
\hline \multirow{2}{*}{$\begin{array}{c}\text { Order } \\
\nu\end{array}$} & \multicolumn{5}{|c|}{ Winding Factors } & \multicolumn{2}{|c|}{ Rotating MMF } \\
\hline & $k_{\mathrm{p} \nu}$ & $k_{\mathrm{d} \nu}$ & $k_{\mathrm{w} \nu}$ & $k_{\mathrm{r} \nu-1}$ & $k_{\mathrm{r} \nu+1}$ & forward & backward \\
\hline 1 & 0.3420 & 0.1774 & 0.0607 & 1.0000 & 0.0000 & 0.0607 & - \\
\hline 2 & 0.6428 & -0.2176 & -0.1398 & 0.0000 & 1.0000 & . & 0.1398 \\
\hline 3 & 0.8660 & -0.6667 & -0.5774 & 0.0000 & 0.0000 & & - \\
\hline 4 & 0.9848 & -0.9598 & -0.9452 & 1.0000 & 0.0000 & 0.9452 & - \\
\hline 5 & 0.9848 & -0.9598 & -0.9452 & 0.0000 & 1.0000 & & 0.9452 \\
\hline 6 & 0.8660 & -0.6667 & -0.5774 & 0.0000 & 0.0000 & - & - \\
\hline 7 & 0.6428 & -0.2176 & -0.1398 & 1.0000 & 0.0000 & 0.1398 & - \\
\hline 8 & 0.3420 & 0.1774 & 0.0607 & 0.0000 & 1.0000 & & 0.0607 \\
\hline 9 & 0.0000 & 0.3333 & 0.0000 & 0.0000 & 0.0000 & & - \\
\hline 10 & -0.3420 & 0.1774 & -0.0607 & 1.0000 & 0.0000 & 0.0607 & - \\
\hline 11 & -0.6428 & -0.2176 & 0.1398 & 0.0000 & 1.0000 & & 0.1398 \\
\hline 12 & -0.8660 & -0.6667 & 0.5774 & 0.0000 & 0.0000 & & 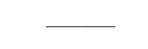 \\
\hline 13 & -0.9848 & -0.9598 & 0.9452 & 1.0000 & 0.0000 & 0.9452 & $\longrightarrow$ \\
\hline 14 & -0.9848 & -0.9598 & 0.9452 & 0.0000 & 1.0000 & & 0.9452 \\
\hline 15 & -0.8660 & -0.6667 & 0.5774 & 0.0000 & 0.0000 & & 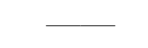 \\
\hline 16 & -0.6428 & -0.2176 & 0.1398 & 1.0000 & 0.0000 & 0.1398 & - \\
\hline 17 & -0.3420 & 0.1774 & -0.0607 & 0.0000 & 1.0000 & & 0.0607 \\
\hline 18 & 0.0000 & 0.3333 & 0.0000 & 0.0000 & 0.0000 & & - \\
\hline
\end{tabular}

Table 4: Winding factors and rotating MMF components for $r=2, s=2, m=3$, and $z=2$

\begin{tabular}{|c|c|c|c|c|c|c|c|}
\hline \multirow{2}{*}{$\begin{array}{c}\text { Order } \\
\nu\end{array}$} & \multicolumn{5}{|c|}{ Winding Factors } & \multicolumn{2}{|c|}{ Rotating MMF } \\
\hline & $k_{\mathrm{p} \nu}$ & $k_{\mathrm{d} \nu}$ & $k_{\mathrm{w} \nu}$ & $k_{\mathrm{r} \nu-1}$ & $k_{\mathrm{r} \nu+1}$ & forward & backwarc \\
\hline 1 & 0.2588 & 0.2588 & 0.0670 & 1.0000 & 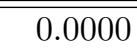 & 0.0670 & 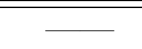 \\
\hline 2 & 0.5000 & 0.0000 & 0.0000 & 0.6667 & -0.3333 & 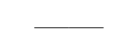 & 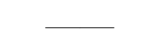 \\
\hline 3 & 0.7071 & 0.7071 & 0.5000 & 0.0000 & 0.0000 & & \\
\hline 4 & 0.8660 & 0.0000 & 0.0000 & -0.3333 & 0.6667 & & - \\
\hline 5 & 0.9659 & 0.9659 & 0.9330 & 0.0000 & 1.0000 & & 0.9330 \\
\hline 6 & 1.0000 & 0.0000 & 0.0000 & 0.6667 & 0.6667 & - & - \\
\hline 7 & 0.9659 & 0.9659 & 0.9330 & 1.0000 & 0.0000 & 0.9330 & $\overline{-3}$ \\
\hline 8 & 0.8660 & 0.0000 & 0.0000 & 0.6667 & -0.3333 & & \\
\hline 9 & 0.7071 & 0.7071 & 0.5000 & 0.0000 & 0.0000 & & \\
\hline 10 & 0.5000 & 0.0000 & 0.0000 & -0.3333 & 0.6667 & & \\
\hline 11 & 0.2588 & 0.2588 & 0.0670 & 0.0000 & 1.0000 & & 0.0670 \\
\hline 12 & 0.0000 & 0.0000 & 0.0000 & 0.6667 & 0.6667 & - & 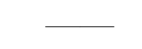 \\
\hline 13 & -0.2588 & -0.2588 & 0.0670 & 1.0000 & 0.0000 & 0.0670 & 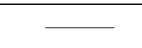 \\
\hline 14 & -0.5000 & 0.0000 & 0.0000 & 0.6667 & -0.3333 & & \\
\hline 15 & -0.7071 & -0.7071 & 0.5000 & 0.0000 & 0.0000 & & \\
\hline 16 & -0.8660 & 0.0000 & 0.0000 & -0.3333 & 0.6667 & & - \\
\hline 17 & -0.9659 & -0.9659 & 0.9330 & 0.0000 & 1.0000 & & 0.9330 \\
\hline 18 & -1.0000 & 0.0000 & 0.0000 & 0.6667 & 0.6667 & - & - \\
\hline 19 & -0.9659 & -0.9659 & 0.9330 & 1.0000 & 0.0000 & 0.9330 & 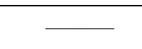 \\
\hline 20 & -0.8660 & 0.0000 & 0.0000 & 0.6667 & -0.3333 & & 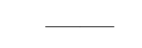 \\
\hline 21 & -0.7071 & -0.7071 & 0.5000 & 0.0000 & 0.0000 & & \\
\hline 22 & -0.5000 & 0.0000 & 0.0000 & -0.3333 & 0.6667 & & $\longrightarrow$ \\
\hline 23 & -0.2588 & -0.2588 & 0.0670 & 0.0000 & 1.0000 & & 0.0670 \\
\hline 24 & 0.0000 & 0.0000 & 0.0000 & 0.6667 & 0.6667 & & $\longrightarrow$ \\
\hline
\end{tabular}

\section{Determination of Pole Number}

For a given stator winding, possible numbers of poles are determined according to the winding factors obtained from (28). For a well-designed stator core, the MMF distribution generates an almost 
Table 5: General expressions of the harmonic order for the maximum absolute value of the winding factor using a positive integer $n$

\begin{tabular}{|c|c|c|c|}
\hline \multirow{2}{*}{$r$} & \multirow{2}{*}{$s$} & \multicolumn{2}{|c|}{$m z$} \\
\hline & & odd & even \\
\hline 1 & 1 & \multicolumn{2}{|c|}{$\nu=(2 n-1) s m z \pm 1$} \\
\hline & & & \\
\hline \multirow{3}{*}{2} & 1 & $\mu=\frac{(2 n-1) s m z}{1}+\frac{1}{2}$ & \multirow{3}{*}{$\nu=\frac{(2 n-1) s m z}{2} \pm 1$} \\
\hline & & $\nu=\frac{2}{2} \overline{2}$ & \\
\hline & 2 & $\nu=\frac{(2 n-1) s m z}{2} \pm 2$ & \\
\hline
\end{tabular}

Table 6: List of the harmonic order for the maximum absolute value of the winding factor for $m=3$ including optimal numbers of poles for the winding layouts

\begin{tabular}{|c|c|c|l||c|c|}
\hline$r$ & $s$ & $z$ & \multicolumn{1}{|c|}{$\nu$} & $Q$ & $2 p$ \\
\hline \multirow{6}{*}{1} & & 1 & $2,4,8,10,14,16, \cdots$ & 6 & 4,8 \\
& & 2 & $5,7,17,19,29,31, \cdots$ & 12 & 10,14 \\
& & 3 & $8,10,26,28,44,46, \cdots$ & 18 & 16,20 \\
& & 4 & $11,13,35,37,59,61, \cdots$ & 24 & 22,26 \\
\cline { 2 - 6 } & & 1 & $5,7,17,19,29,31, \cdots$ & 12 & 10,14 \\
& 2 & 2 & $11,13,35,37,59,61, \cdots$ & 24 & 22,26 \\
& & 3 & $17,19,53,55,89,91, \cdots$ & 36 & 34,38 \\
& & 4 & $23,25,71,73,119,121, \cdots$ & 48 & 46,50 \\
\hline \multirow{4}{*}{2} & & 1 & $1,2,4,5,7,8, \cdots$ & 3 & 2,4 \\
& & 2 & $2,4,8,10,14,16, \cdots$ & 6 & 4,8 \\
& & 3 & $4,5,13,14,22,23, \cdots$ & 9 & 8,10 \\
& & 4 & $5,7,17,19,29,31, \cdots$ & 12 & 10,14 \\
\hline & & 1 & $1,5,7,11,13,17, \cdots$ & 6 & 2,10 \\
& 2 & 2 & $5,7,17,19,29,31, \cdots$ & 12 & 10,14 \\
& & 3 & $7,11,25,29,43,47, \cdots$ & 18 & 14,22 \\
& & 4 & $11,13,35,37,59,61, \cdots$ & 24 & 22,26 \\
\hline
\end{tabular}

identical spatiotemporal distribution of magnetic flux across the air gap. However, the harmonic components whose order is much larger or much smaller than half of the slot number tend to be reduced because of the angular variation in the stator magnetic reluctance and fringing flux around the sides of the stator teeth.

In a repeatable group, the rotor with the $p$ pole pair synchronises with the $p$-th harmonic component of the rotating magnetic flux [6]. The rotational direction is the same as that of the synchronised component and the rotational velocity is $\omega / p$. If magnetic saturation is negligible, the average torque is proportional to the amplitude of the synchronised component. The other components give rise to pulsating torques in proportion to their amplitudes. Therefore, the orders of the existing harmonic components correspond to the possible numbers of pole pairs. Among the numbers, the optimal numbers are determined considering the absolute values of the winding factors. The harmonic components corresponding to the maximum absolute value of the winding factor are selected to achieve a torque production with high average and low pulsation. That is, the optimal numbers of pole pairs are equal to the harmonic orders for the maximum absolute value of the winding factor.

The functions of the general expressions for the winding factor are examined to obtain the harmonic orders for the maximum absolute value. In the single-layer winding configurations, $r=1$, the 


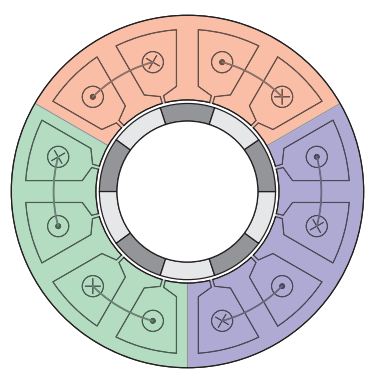

(a) $r=1$ and $s=1$

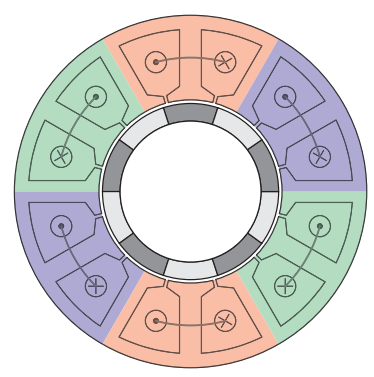

(b) $r=1$ and $s=2$

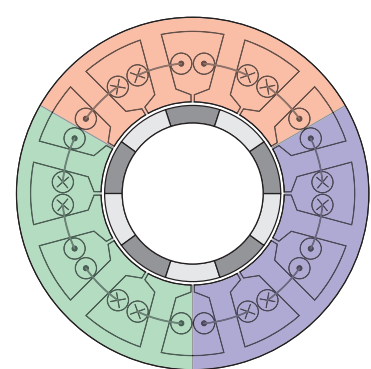

(c) $r=2$ and $s=1$

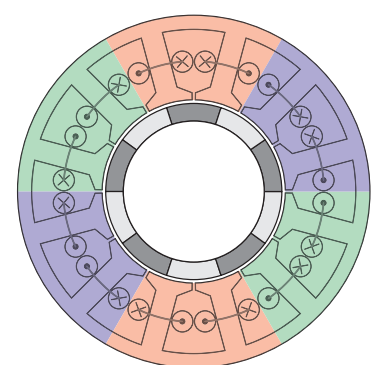

(d) $r=2$ and $s=2$

Fig. 5: Winding layouts for the 12 -slot 10-pole combination

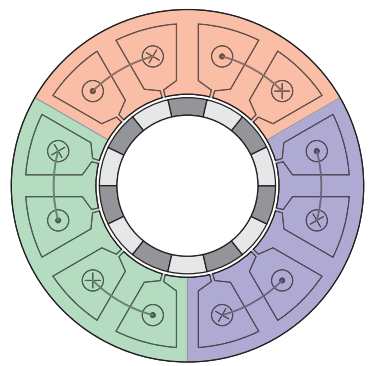

(a) $r=1$ and $s=1$

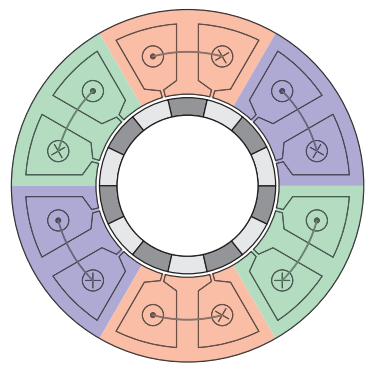

(b) $r=1$ and $s=2$

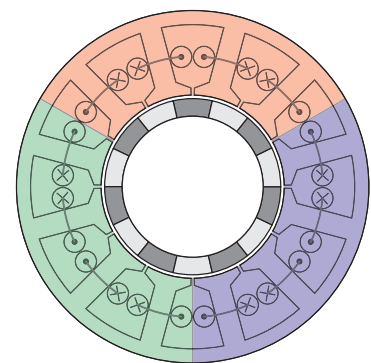

(c) $r=2$ and $s=1$

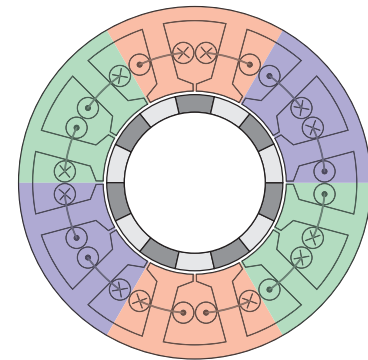

(d) $r=2$ and $s=2$

Fig. 6: Winding layouts for the 12-slot 14-pole combination

absolute value of the winding factor is maximised at $\nu=(2 n-1) s m z \pm 1$ for a positive integer $n$. In the double-layer winding configurations, $r=2$, the maximum is given at $\nu=(2 n-1) \operatorname{smz} / 2 \pm 1 / 2$ if $s m z$ is odd, $\nu=(2 n-1) s m z / 2 \pm 1$ if $m z$ is even, and $\nu=(2 n-1) s m z / 2 \pm 2$ if $s=2$ and $m z$ is odd. Tables 5 and 6 summarise these general expressions and the list of the orders for $m=3$. These orders are consistent with Tables 2, 3, and 4 . The winding layouts with the optimal numbers of poles, $2 p=10$ and 14, for the number of slots, $Q=12$, are shown in Figs. 5 and 6 , respectively. These figures imply that these winding layouts are designed regardless of the number of poles. In addition, the winding factors of the maximum absolute values are coincident with the conventional winding factors, which are defined in electrical degrees, for the corresponding slot/pole combinations that are obtained in [17-19].

\section{FEM Analysis}

The performance of surface-mounted permanent magnet synchronous motors equipped with identical fractional-slot concentrated windings is examined through an FEM analysis. A stator with a fractional-slot concentrated winding is constructed as the stator common to different rotors that have possible numbers of poles. Based on the obtained winding factors, the numbers of poles are selected among the harmonic orders that are close to half of the slot numbers because the other harmonics are reduced in the generated flux distribution.

The stator winding for $r=2, s=1, m=3$, and $z=3$, as shown in Fig. 4a, is selected. The number of slots is $Q=9$. The winding supplied with a three-phase current generates the spatiotemporal distribution of the MMF that includes the rotating components described in Table 3. For the order less than the slot number, $\nu \leq 9$, the non-zero winding factors appear at $\nu=1,2,4,5,7$, and 8 , as shown in Fig. 7. The orders can be selected as the possible numbers of pole pairs. Among the 


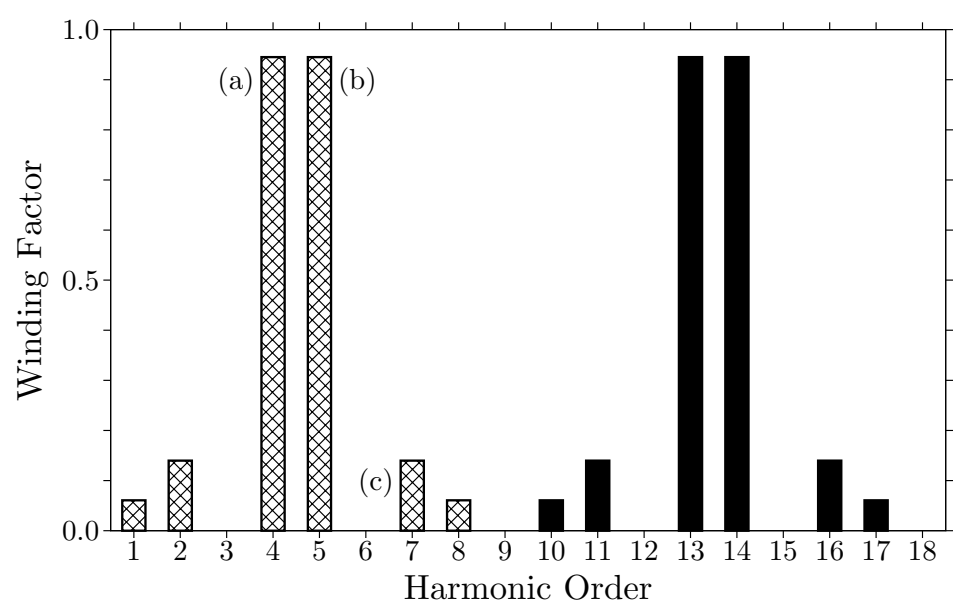

Fig. 7: Harmonic components of the winding factor for $r=2, s=1, m=3$, and $z=3$. The labels (a), (b), and (c) indicate the models in Fig. 8.

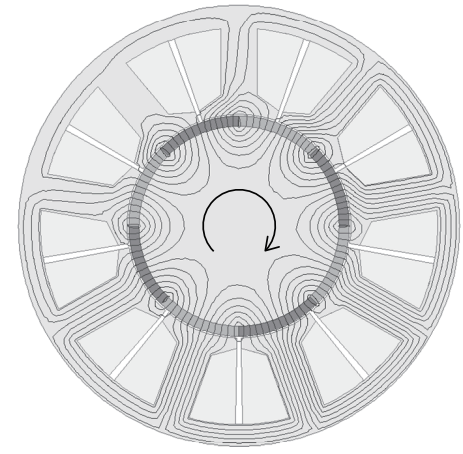

(a)

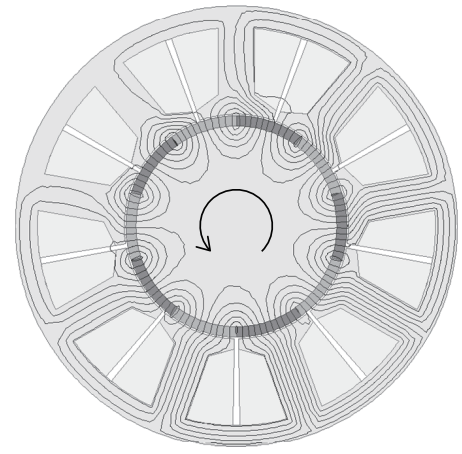

(b)

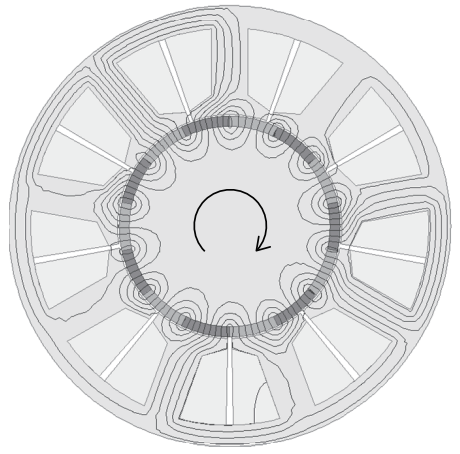

(c)

Fig. 8: Flux distributions of motors consisting of identical 9-slot stators equipped with the fractional-slot concentrated windings and different pole rotors: (a) 8-pole, (b) 10-pole, and (c) 14-pole.

Table 7: Performance of the motors, as shown in Fig. 8, with different numbers of poles for a supply current with the amplitude of $4 \mathrm{~A}$ and the frequency of $42 \mathrm{~Hz}$

\begin{tabular}{crrrrr}
\hline $\begin{array}{c}\text { Number } \\
\text { of Poles }\end{array}$ & $\begin{array}{c}\text { Rotational } \\
\text { Speed }\end{array}$ & $\begin{array}{c}\text { Rotational } \\
\text { Direction }\end{array}$ & $\begin{array}{c}\text { Average } \\
\text { Torque }\end{array}$ & $\begin{array}{c}\text { Ripple } \\
\text { Factor }\end{array}$ & $\begin{array}{c}\text { Synchronous } \\
\text { No-load EMF }\end{array}$ \\
\hline \hline 2 & $2520 \mathrm{rpm}$ & forward & $0.12 \mathrm{~N} \cdot \mathrm{m}$ & $1783.0 \%$ & $6.0 \mathrm{~V}$ \\
4 & $1260 \mathrm{rpm}$ & backward & $0.61 \mathrm{~N} \cdot \mathrm{m}$ & $445.6 \%$ & $12.7 \mathrm{~V}$ \\
8 & $630 \mathrm{rpm}$ & forward & $5.16 \mathrm{~N} \cdot \mathrm{m}$ & $7.1 \%$ & $58.2 \mathrm{~V}$ \\
10 & $504 \mathrm{rpm}$ & backward & $5.57 \mathrm{~N} \cdot \mathrm{m}$ & $8.8 \%$ & $50.4 \mathrm{~V}$ \\
14 & $360 \mathrm{rpm}$ & forward & $0.87 \mathrm{~N} \cdot \mathrm{m}$ & $99.9 \%$ & $5.6 \mathrm{~V}$ \\
16 & $315 \mathrm{rpm}$ & backward & $0.41 \mathrm{~N} \cdot \mathrm{m}$ & $378.0 \%$ & $2.1 \mathrm{~V}$ \\
\hline
\end{tabular}

winding factors, the maximum absolute value is 0.9452 at $\nu=4$ and 5 . Hence, the optimal numbers of pole pairs are 4 and 5 .

A three-phase current is supplied to the motors with different numbers of poles. For each phase of the supply current, the amplitude of phase currents is $I_{\text {peak }}=4 \mathrm{~A}$, the frequency is $f=\omega / 2 \pi=42 \mathrm{~Hz}$, and the phase is $\theta_{0}=0^{\circ}$. The current includes only the q-axis component on vector control. The analysed models for the 8-pole, 10-pole, and 14-pole motors are shown in Fig. 8. The performance of the motors is presented in Table 7 . The rotational directions are consistent with those of the rotating MMF components of the corresponding order in Table 3. This implies that the rotors synchronise with the corresponding MMF components. The produced torque is approximately proportional 


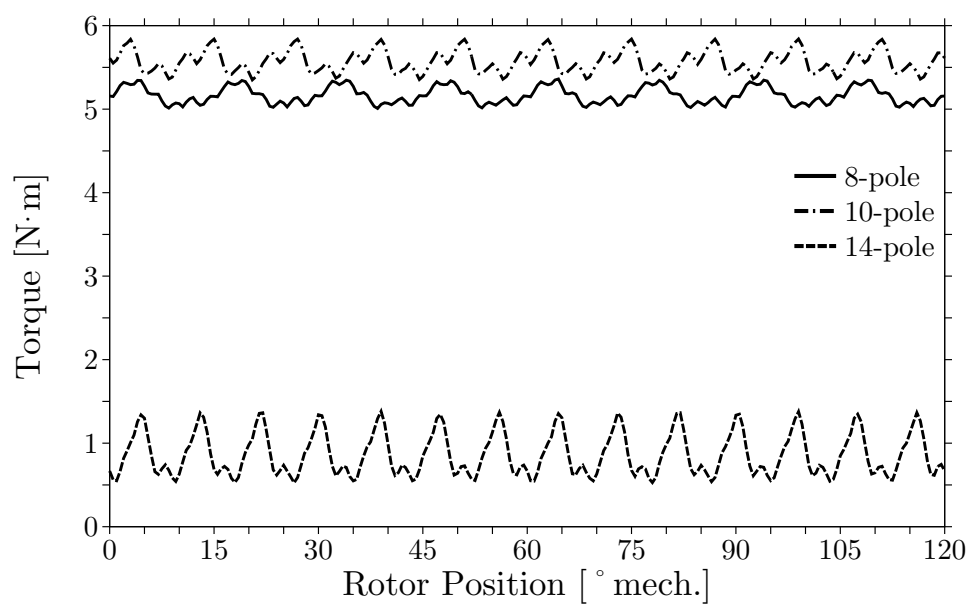

Fig. 9: Torque produced in the motors, as shown in Fig. 8, with different numbers of poles for a supply current with the amplitude of $4 \mathrm{~A}$ and the frequency of $42 \mathrm{~Hz}$

to the amplitude of the synchronised MMF components and the number of poles. Therefore, the analysis validates the determination of the optimal numbers of poles based on the winding factor. In addition, the torque pulsation or the ripple factor in Table 7 can be approximately estimated from the winding factors of non-synchronous order. Fig. 9 shows the torque produced in the motors with different numbers of poles. For reference, Table 7 includes the amplitude of the synchronised components in the no-load EMFs. Magnetic saturation in stator cores reduces the average torques and the synchronised EMFs for the small numbers of poles or $2 p=2,4$.

\section{Conclusion}

This paper performs the general formulation of the winding factor for the fractional-slot concentrated windings. The winding factor is redefined for winding configurations without any information of the number of poles. For the winding configurations, the optimal numbers of poles are selected among the orders of the maximum absolute value of the winding factor. The design of the winding configuration, including the determination of the number of poles, is verified through an FEM analysis. The derived general expression is expected to serve as a powerful tool to obtain the winding factor in the design of the fractional-slot concentrated windings because it requires no procedures. However, the general expression, which is derived for the restricted winding configurations with concentrated windings, cannot cover all slot/pole combinations. Hence, the derived expression is not applied to the fractionalslot overlapping winding configurations. In the future, based on this achievement, it is hoped that a general expression can be derived for the optimal winding configurations of all slot/pole combinations obtained in $[6,17,18]$.

\section{References}

[1] EL-Refaie, A.M.: 'Fractional-slot concentrated-windings synchronous permanent magnet machines: opportunities and challenges', IEEE Trans. Ind. Electron., 2010, 57, (1), pp. 107-121 
[2] Jack, A.G., Mecrow, B.C., Dickinson, P.G., et al.: 'Permanent-magnet machines with powdered iron cores and prepressed windings', IEEE Trans. Ind. Appl., 2000, 36, (4), pp. 1077-1084

[3] Akita, H., Nakahara,Y., Miyake, N., Oikawa, T.: 'New core structure and manufacturing method for high efficiency of permanent magnet motors', Conf. Rec. IEEE IAS Annu. Meeting, Salt Lake City, UT, USA, Oct. 2003, 2, pp. 367-372

[4] Shen, J., Wang, C., Miao, D., Jin, M., Shi, D., Wang, Y.: 'Analysis and optimization of a modular stator core with segmental teeth and solid back iron for pm electric machines', Proc. IEEE-IEMDC, Niagara Falls, ON, Canada, May 2011, pp. 1270-1275

[5] Mitcham, A.J. Antonopoulos, G., Cullen, J.J.A.: 'Favourable slot and pole number combinations for fault-tolerant PM machines', IEE Proc.-Electr. Power Appl., 2004, 151, (5), pp. 520-525

[6] Bianchi, N., Bolognani, S., Pré, M.D., Grezzani, G.: 'Design considerations for fractional-slot winding configurations of synchronous machines', IEEE Trans. Ind. Appl., 2006, 42, (4), pp. 9971006

[7] Prieto, B., Martínez-Iturralde, M., Fontán, L., Elosegui, I.: 'Fault-tolerant permanent magnet synchronous machine - phase, pole and slot number selection criterion based on inductance calculation', IET Electr. Power Appl., 2015, 9, (2), pp. 138-149

[8] Dutta, R., Rahman, M.F. Chong, L.: 'Winding inductances of an interior permanent magnet (IPM) machine with fractional slot concentrated winding', IEEE Trans. Magn., 2012, 48, (12), pp. $4842-4849$

[9] Ponomarev, P., Lindh, P., Pyrhönen, J.: 'Effect of slot-and-pole combination on the leakage inductance and the performance of tooth-coil permanent-magnet synchronous machines', IEEE Trans. Ind. Electron., 2013, 60, (10), pp. 4310-4317

[10] Ni, R., Wang, G., Gui, X., Xu, D.: 'Investigation of $d$ - and $q$-axis inductances influenced by slotpole combinations based on axial flux permanent-magnet machines', IEEE Trans. Ind. Electron., 2014, 61, (9), pp. 4539-4551

[11] Ponomarev, P., Alexandrova, Y., Petrov, I., Lindh, P., Lomonova, E., Pyrhönen, J.: 'Inductance calculation of tooth-coil permanent-magnet synchronous machines', IEEE Trans. Ind. Electron., 2014, 61, (11), pp. 5966-5973

[12] Magnussen F., Sadarangani, C.: 'Winding factors and Joule losses of permanent magnet machines with concentrated windings', Proc. IEEE-IEMDC, Madison, WI, USA, Jun. 2003, pp.333339

[13] Bianchi, N., Fornasiero, E.: 'Index of rotor losses in three-phase fractional-slot permanent magnet machines', IET Electr. Power Appl., 2009, 3, (5), pp. 381-388

[14] Fornasiero, E., Bianchi, N., Bolognani, S.: 'Slot harmonic impact on rotor losses in fractional-slot permanent-magnet machines', IEEE Trans. Ind. Electron., 2012, 59, (6), pp. 2557-2564

[15] Fornasiero, E., Alberti, L., Bianchi, N., Bolognani, S.: 'Considerations on selecting fractionalslot nonoverlapped coil windings', IEEE Trans. Ind. Appl., 2013, 49, (3), pp. 1316-1324 
[16] Bianchi, N., Pré, M.D., Alberti, L., Fornasiero, E.: 'Theory and design of fractional-slot PM machines'. IEEE IAS Tutorial Course Notes, IAS'07 Annual Meeting, New Orleans, LA, September 2007

[17] Cros, J., Viarouge, P.: 'Synthesis of high performance PM motors with concentrated windings', IEEE Trans. Energy Covers., 2002, 17, (2), pp.248-253

[18] EL-Refaie, A.M., Shah, M.R., Qu, R., Kern, J.M.: 'Effect of number of phases on losses in conducting sleeves of surface PM machine rotors equipped with fractional-slot concentrated windings', IEEE Trans. Ind. Appl., 2008, 44, (5), pp. 1522-1532

[19] Libert, F., Soulard, J.: 'Investigation on pole-slot combinations for permanent-magnet machines with concentrated windings', Proc. ICEM, Cracow, Poland, Sep. 2004, pp. 530-535

[20] Bianchi, N., Pré, M.D.: 'Use of the star of slots in designing fractional-slot single-layer synchronous motors', IEE Proc.-Electr. Power Appl., 2006, 153, (3), pp. 459-466

[21] Chalmers, B.J.: 'A.C. machine windings with reduced harmonic content', Proc. Inst. Elect. Eng., 1964, 111, (11), pp. 1859-1863 